\title{
Black Seed (Nigella sativa) Efficacy in Improving Clinical Symptoms and Interleukin-6 Levels Schizophrenic Patients
}

\author{
Sri Purwatiningsih*, Saidah Syamsuddin (D), Sonny T. Lisal, Kristian Liaury, Burhanuddin Bahar, Ika Yustisia \\ Department of Psychiatry, Faculty of Medicine, Hasanuddin University, Makassar, South Sulawesi, Indonesia
}

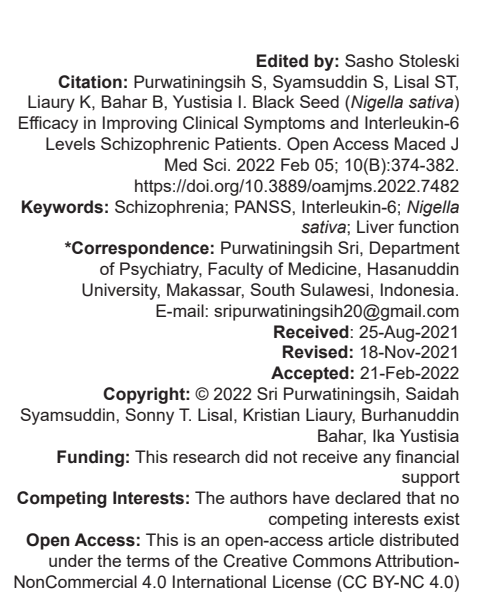

\section{Introduction}

Schizophrenia can be understood as a neurodevelopmental disorder with onset usually in early adulthood [1]. A complex multidimensional syndrome characterized by positive symptoms (e.g., delusions and hallucinations), negative symptoms (e.g., motivational disturbances), affective dysregulation (e.g., depression, mania, or anxiety), and cognitive changes [2]. Schizophrenia is a multisystem disorder with a global prevalence of $0.33-0.75 \%$ and is one of the top 15 causes of disability. The etiology underlying the disease is still controversial and not fully understood [3].

Abnormal activation of the immune system over the years has been associated with schizophrenia. Inflammation may play a role in the pathogenesis of psychosis, based on the presence of immunological anomalies in schizophrenia through innate and acquired immune responses, and the consequent increase in specific cytokines and inflammatory mediators such as Interleukin (IL)-6 and CRP [2]. High levels of proinflammatory substances such as cytokines are found in the blood and cerebrospinal fluid of schizophrenic patients. Further, the inflammatory hypothesis stems from the therapeutic benefits of anti-inflammatory drugs. Meta-analyses have demonstrated a beneficial effect of celecoxib and aspirin in schizophrenia. In addition, the anti-inflammatory and immunomodulatory effects of antipsychotics have been known for a long time [4].

Nigella sativa (black seed or black cumin), is an annual plant with many pharmacological properties. The use of $N$. sativa seeds and oil in traditional medicine has been used for more than 2000 years [5]. N. sativa has the most important active components, namely Thymoquinone (TQ) [6]. In the field of neuropsychiatry, it has been shown that $N$. sativa modulates mood, anxiety, and cognition in healthy young men [7]. N. sativa prevents depressive behavior in LPS-induced mice [8]. N. sativa is neuroprotective [9], [10], [11], nephroprotective [12], and hepatoprotective [13] in several animal studies. In a study of forty elderly $N$. sativa can improve memory, attention and cognition [14]. According to one study $T Q$ reduces neutrophil accumulation, inhibits polymorphonuclear function in vitro and in vivo. In addition, it can inhibit inflammatory cytokines such as IL-1 and IL-6. TQ exerts anti-inflammatory properties by inhibiting their production [6]. 
Effects of TQ on hippocampal cytokine levels, oxidative stress, and cognitive memory impairments in rats produced by lipopolysaccharide (LPS). Protects against oxidative injury, antioxidant, anti-inflammatory, and acetyl cholinesterase inhibitory activities can induce memory impairment. As a result, study discovered that TQ boosts its anti-inflammatory and neuroprotective properties. $N$. sativa and TQ have traditionally and experimentally been used to treat a variety of degenerative disorders, including Parkinson's, Alzheimer's, and schizophrenia. TQ appears to improve learning and reduce LPS-induced memory impairment in mice, according to the findings of this study by reducing hippocampus cytokine levels and brain tissue oxidative damage [15].

$\mathrm{TQ}$ is an antioxidant phytochemical that has been found to reduce inflammation in the nervous system. TQ inhibited NF-B-dependent neuroinflammation in BV2 microglia by targeting an antioxidant pathway involving activation of nuclear erythroid 2 related factor 2/antioxidant response element, possibly leading to inhibitory neuroinflammation mediated by NF-B, according to one study. TQ reduced TNF, IL-6, and IL-1 mRNA levels in LPS-activated mice's primary microglia [16].

Another study evaluated at the antiinflammatory effects of TQ in BV-2 murine microglial cells treated with LPS. TQ efficiently lowered $\mathrm{NO}_{2}$ with an IC50 of $5.04 \mu \mathrm{M}$ when compared to the specific iNOS inhibitor LNIL-L-N6-(1-iminoethyl) lysine, according to the findings $\left(\mathrm{IC}_{50} 4.09 \mu \mathrm{M}\right)$. Using the rayBio antibody protein array AAM-CYT-3 and 4 cytokines, the antiinflammatory effect of TQ ninety-six (96) cytokines was also assessed. BV-2 cells generated a substantial increase in specific pro-inflammatory cytokines such as the chemokines IL-6, IL-12p40/70, CCL12/MCP-5, CCL2/MCP-1, and G-CSF in the presence of LPS $(1 \mathrm{~g} / \mathrm{ml})$, which was decreased by the addition of TQ $(10 \mu \mathrm{M})$ [9].

Effects of $N$. sativa supplementation on inflammation and oxidative stress as indicators in a systematic review and meta-analysis of controlled clinical trials showed a significant reduction in CRP concentrations [17]. In addition, research on sepsisaffected mice found that TQ has an active inflammatory response in relation to early-stage biomarkers and can detect sepsis-related mortality. The information presented here indicates that TQ has the potential to be a therapeutic value in the treatment of sepsis. TQ $1 \mathrm{mg} / \mathrm{kg}$ i.p. postdose infection aided significant inhibition of the levels of cytokines, namely TNF-, IL-1, IL-2, IL-6, and IL-10 [18].

In a systematic review and meta-analysis of controlled clinical studies, the effects of $N$. sativa supplementation on inflammation and oxidative stress as markers revealed a considerable reduction in CRP concentrations [17]. (Mohit et al., 2020) Furthermore, studies on sepsis-affected mice have discovered that $\mathrm{TQ}$ has an active inflammatory response in relation to early-stage indicators and can detect sepsis-related death. According to the information presented here, TQ may have therapeutic utility in the treatment of sepsis. TNF-, IL-1, IL-2, IL-6, and IL-10 levels were significantly reduced by TQ $1 \mathrm{mg} / \mathrm{kg}$ i.p. after a dose of infection [18].

The pharmacological effect of crude $N$. sativa extract (and some of its active constituents, e.g., essential oil and TQ) is protection against nephrotoxicity and hepatotoxicity caused by disease or chemicals. The seeds/oil have anti-inflammatory, analgesic, antipyretic, antimicrobial, and antineoplastic activities. The oil lowers blood pressure and improves breathing. Treatment of mice with $N$. sativa extract for up to 12 weeks has been reported to cause changes in hemograms that increase packed cell volume and hemoglobin, and decrease plasma concentrations of cholesterol, triglycerides, and glucose. Seeds are characterized by a very low level of toxicity. Two cases of contact dermatitis in two persons have been reported following topical use. Administration of the seed extract or its oil has been shown to not cause significant side effects on liver or kidney function. The beneficial effects of the use of whole grains and $T Q$ are related to their cytoprotective and antioxidant actions, and their effects on several mediators of inflammation [19]. In one study, N. sativa up to $1 \mathrm{~g} \mathrm{~kg} 1$ was added for 28 days, resulting in no change in liver enzyme levels and no toxic effect on liver function [20]. In addition, the toxicity of NSFO in mice and rats was tested, through LD50 assessment and examination of possible biochemical, hematological and histopathological changes. No changes were observed in the levels of major liver enzymes, including aspartate aminotransferase (AST), alanine aminotransferase $(\mathrm{ALT})$, and GGT and histopathological modifications (heart, liver, kidney, and pancreas) in mice [21].

According to one study, co-administration of TQ or TQ-containing compounds with medicines metabolized by CYP enzymes, specifically CYP2C9, may cause a pharmacological interaction. In human liver microsomes, the effects of TQ on the metabolic activity of four key drug-metabolizing enzymes: Cytochrome P450 (CYP) 1A2, CYP2C9, CYP2D6, and CYP3A4. TQ inhibits CYP enzyme activity by incubating usual substrates with it (phenacetin for CYP1A2, tolbutamide for CYP2C9, dextromethorphan for CYP2D6, and testosterone for CYP3A4) [22]. The extract of $N$. sativa inhibits cytochrome P-450 3A4, 2C9, 3A5, and $3 A 7$ in humans through cDNA-mediated inhibition of cytochrome P-450 3A4, 2C9, 3A5, and 3A7, which can impact and/or decrease the metabolism of numerous medications, according to in vitro investigations. Both methanol extract and Nigella hexane considerably boosted amoxicillin permeability in vitro ( $p$ 0.001) as compared to controls. At the same dose level, permeation was found to be substantially higher for the hexane extract ( $p$ 0.001) than for the methanol extract ( $p$ 0.001). In both in vivo and in vitro experiments, Nigella boosted amoxicillin levels [23]. Hence, it is necessary to pay attention to its long-term effect on the metabolism of risperidone in the liver which is inhibited by TQ. 
There is one study looking at the role of TQ on day 28 after administration of TQ (20 mg/kg, i.p.) alone or in combination compared to control, it can reduce dopamine (DA) levels in experimental animals through induction of apomorphine and scopolamine [24]. In a preliminary study conducted in 2020 regarding N. sativa as an adjuvant therapy that improves clinical, cognitive, and extrapyramidal symptoms in schizophrenic patients receiving risperidone therapy in 20 research subjects, where clinical symptom improvement was significant with the administration of $1000 \mathrm{mg} \mathrm{N}$. sativa through Positive and Negative Syndrome Scale (PANSS) for schizophrenia assesment which was expected can reduce length of stay. There has never been a study to improve symptoms of schizophrenia by administering $N$. sativa as adjuvant to schizophrenia patients by measuring changes in IL-6 cytokine levels as a marker of therapeutic effectiveness.

\section{Methods}

\section{Sample}

This research is an experimental research that was conducted at the Regional Special Hospital of South Sulawesi Province in March to May 2021. The population in this study were all new schizophrenic patients who were hospitalized at the Regional Special Hospital of South Sulawesi Province for the period of March to May 2021 who met the inclusion criteria.

Inclusion criteria, in this study, namely, patients aged 20-45 years who met the criteria for schizophrenia according to PPDGJ III, new or recurring schizophrenic patients with acute exacerbations of at least a PANSS value of 100 , who received the antipsychotic drug risperidone 2-4 mg tablets/day. Exclusion criteria for patients suffering from general medical disorders, pregnancy, and a history of being using anti-inflammatory drugs and antibiotics. Samples were dropped out when they returned home at the request of themselves or their families before the study was completed or died.

\section{Procedure}

Every patient who met the criteria for schizophrenia according to PPDGJ III who matched the inclusion and exclusion criteria in the study group was recorded and a history of past disease was analyzed. The researcher then explained to the family and research subjects the aims and objectives of the study. If agreed, the subject will be included in the research. Subjects were divided into two groups, namely, the control group which was treated only risperidone and the group treated with risperidone accompanied by giving $N$. sativa. The PANSS score and serum IL-6 levels were determined in both groups at baseline before giving $N$. sativa $1000 \mathrm{mg} /$ day and 4 weeks later. Giving $N$. sativa by called one by one before lunch by the nurse to immediately take the $N$. sativa capsules that had been given. Risperidone $2 \mathrm{mg}$ is given twice in the morning and evening in the same manner as for $N$. sativa. The measurement of the PANSS value is based on interviews with patients and nurse observations. In addition, assessing body mass index (BMI), taking blood for examination of IL-6 and liver function in the treatment group. Then perform data analysis to determine differences in PANSS values and serum IL-6 levels at week 0 and week 4 . Healthy control hired by interviews of people who did not have severe mental disorders according to the PPDGJ III diagnostic criteria. Not suffering from illness, fever, and taking anti-inflammatory drugs, antibiotics, antioxidants, and psychotropics age range $30-40$ years.

\section{IL-6 serum}

3 cc of venous blood was taken using the phlebotomy technique and centrifuged to obtain serum fluid. The tool used to measure serum IL- 6 levels is the human IL-6 ELISA essay kit. Has a size of $1 \times 96$ wells, sensitivity $0.96 \mathrm{ng} / \mathrm{L}$, standard curve range: $2-600 \mathrm{ng} / \mathrm{L}$, with a sample of $20 \mu \mathrm{L}$ serum. Examination of serum IL-6 levels was carried out at the Research Laboratory of the Hasanuddin University Central Hospital. The procedure with prepare all reagents, standard solutions and samples as instructed. Bring all reagents to room temperature before use. The assay is performed at room temperature. After doing all the procedures, then determine the optical density value of each plate well immediately using a microplate reader set to $450 \mathrm{~nm}$ within 10 min after adding the stop solution.

\section{Statistical analysis}

Data were entered into Microsoft Excel. Collecting demographic data and analysis descript research subject analyzed the difference in PANSS and IL- 6 values in the two groups and measuring the percentage of the speed of decreasing the effect of treatment on PANSS and IL-6 levels.

\section{Results}

\section{Characteristics of patients}

This research was conducted in the inpatient room of the Regional Special Hospital of South Sulawesi Province March to May 2021. The sample that met the research inclusion criteria were 22 people which were divided into 2 groups, namely, ten subjects 
Table 1: Socio-demographic characteristics by frequency ( $n=22)$

\begin{tabular}{|c|c|c|c|c|}
\hline Variable & Variable Group & $\mathrm{n}$ & $\%$ & $p$ \\
\hline Gender & Man & 22 & 100 & \\
\hline \multirow[t]{3}{*}{ Age (years) } & $17-25$ & 6 & 27.27 & 0.451 \\
\hline & $26-35$ & 8 & 36.36 & \\
\hline & $36-45$ & 8 & 36.36 & \\
\hline \multirow[t]{3}{*}{ Marital status } & Marry & 3 & 13.6 & 0.304 \\
\hline & Not married yet & 16 & 72.7 & \\
\hline & Divorced & 3 & 13.6 & \\
\hline \multirow[t]{2}{*}{ Work } & Work & 7 & 31.8 & 0.341 \\
\hline & Does not work & 15 & 68.2 & \\
\hline \multirow[t]{3}{*}{ Level of education } & Elementary School & 7 & 31.8 & 0.306 \\
\hline & Junior high school & 5 & 22.7 & \\
\hline & Senior High School & 10 & 45.5 & \\
\hline \multirow[t]{3}{*}{ Inpatient } & 1 time & 5 & 22.7 & 0.488 \\
\hline & $2-10$ times $>10$ times & 12 & 54.6 & \\
\hline & & 5 & 22.7 & \\
\hline \multirow[t]{3}{*}{ Disease Onset } & $<5$ years & 12 & 54.5 & 0.451 \\
\hline & $5-10$ years $>10$ years & 3 & 13.6 & \\
\hline & & 7 & 31.8 & \\
\hline \multirow[t]{3}{*}{ BMI week 0} & Underweight & 2 & 9.1 & 0.571 \\
\hline & Normal & 15 & 68.2 & \\
\hline & Overweight & 5 & 22.7 & \\
\hline \multirow[t]{3}{*}{ BMI week 4} & Underweight & 3 & 14.6 & 0.387 \\
\hline & Normal & 14 & 63.6 & \\
\hline & Overweight & 5 & 22.7 & \\
\hline
\end{tabular}

treatment groups who received $1000 \mathrm{mg}$ black cumin adjuvant and 12 subjects controls. In the descriptive statistics (Table 1), the research subject the research subjects $(n=22)$ were all male $(100 \%)$, most of them were unmarried $(72.7 \%)$, and did not work $(68.2 \%)$. The highest education level of the research subjects was high school (45.5\%). The research subjects averaged 2-10 times of hospitalization $(54.6 \%)$ and the most disease progression was $<5$ years $(54.5 \%)$. BMl was mostly normal, $15(68.2 \%)$ subjects in the $1^{\text {st }}$ week, and 14 people with normal BMI (63.6\%) at week 4 .

\section{(PANSS)}

\section{Positive and negative symptoms scale}

Improvements in the PANSS value in the research subjects are shown in Table 2 . The median PANSS value in the treatment group in the $1^{\text {st }}$ week of 112 decreased to 60 and in the control group the median PANSS value of 110 became 79 . Changes in the PANSS value week 0 and week 4 obtained significant results for both groups $p<0.05$.

Table 2: Comparison of Improvements in PANSS

\begin{tabular}{llll}
\hline Group & PANSS value & $\mathrm{p}$ \\
\cline { 2 - 3 } & $\begin{array}{l}\text { Week 0 } \\
\text { (Minimum-Maximum) }\end{array}$ & $\begin{array}{l}\text { Week 4 } \\
\text { (Minimum-Maximum) }\end{array}$ & \\
\hline Treatment & 115 & 60 & 0.005 \\
& $(100-121)$ & $(53-68)$ & 0.002 \\
Control & 109 & 79 & $(67-93)$ \\
& $(100-125)$ & & \\
\hline
\end{tabular}

Figure 1 shows the comparison of the PANSS baseline and week 4 were showing a significant difference in the PANSS value in the treatment group compared to the treatment with $p<0.001$.

Table 3 shows a comparison of the rate of decline in the value of each PANSS dimension. The decrease was significantly different in positive,

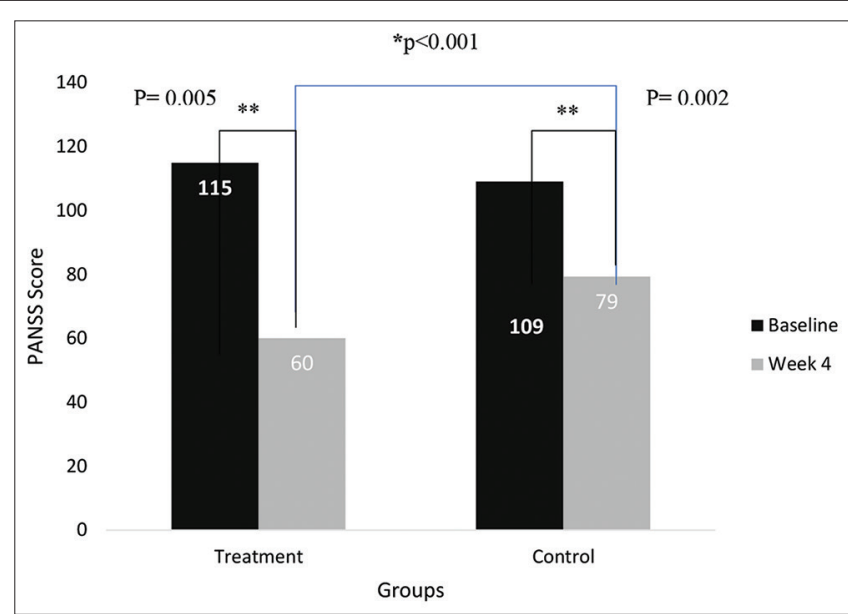

Figure 1: Comparison of PANSS values week-0 and week-4

negative and general symptoms in both the treatment group and the control group. Positive symptoms in the treatment group showed the greatest decrease in the $4^{\text {th }}$ week compared to other symptoms with a significance $<0.001$.

Table 3: Percentage of change rate of PANSS value $(n=22)$

\begin{tabular}{|c|c|c|c|c|c|c|}
\hline \multirow[t]{2}{*}{ Group } & \multicolumn{2}{|c|}{ Positive Symptoms } & \multicolumn{2}{|c|}{ Negative Symptoms } & \multicolumn{2}{|c|}{$\begin{array}{l}\text { General } \\
\text { Psychopathology Scale }\end{array}$} \\
\hline & (\%) & $p$ & (\%) & $p$ & (\%) & $p$ \\
\hline $\begin{array}{l}\text { Treatment } \\
\text { Control }\end{array}$ & $\begin{array}{l}-50.63 \pm 5.41 \\
-29.03 \pm 9.24^{*}\end{array}$ & $<0.001$ & $\begin{array}{l}-48.17 \pm 8.29 \\
-28.76 \pm 16.24^{*}\end{array}$ & 0.001 & $\begin{array}{l}-42.43 \pm 9.16 \\
-27.15 \pm 9.02\end{array}$ & 0.001 \\
\hline
\end{tabular}

\section{Serum IL-6 level}

On examination, the serum levels of IL-6 at week 0 showed that the mean in 14 healthy people was $26.36 \pm 21.78 \mathrm{ng} / \mathrm{L}$, lower than the schizophrenia group with the range of serum IL-6 levels from 0 to $77.3 \mathrm{ng} / \mathrm{L}$. Meanwhile, in the research subjects, the mean serum IL-6 level in the treatment group was $39.6 \pm 43.54 \mathrm{ng} / \mathrm{L}$, the IL-6 value ranged from 10.24 to $158.50 \mathrm{ng} / \mathrm{L}$, and the control group was $51.59 \pm 84.51 \mathrm{ng} / \mathrm{L}$ with a value range of $0-312.17 \mathrm{ng} / \mathrm{L}$. Changes in serum IL-6 levels at week 0 and week 4 were not significant in both groups with a significance of treatment $p=0.241$ and control $p=0.433(p>0.05)($ Table 4$)$.

The difference in serum IL- 6 levels at week 4 was also not significant in the control group compared to the treatment group with $p=0.83(>0.05)$. The mean levels of IL-6 in the treatment group were lower than the control group, $45.74 \pm 44.59 \mathrm{ng} / \mathrm{L}$ compared to $47.20 \pm$ $45.15 \mathrm{ng} / \mathrm{L}$ in the control group. $\mathrm{k}$ range. The serum IL-6 level in the treatment group was 8.1-167.41 $\mathrm{ng} / \mathrm{L}$ and $9.1-180.7 \mathrm{ng} / \mathrm{L}$ in the control group.

Table 5 shows that the percentage rate of change in IL- 6 levels in the treatment group of $36.44 \pm$ 66.46 and the control group was $92.88 \pm 168.24$. This indicates that the biological effect of $N$. sativa on IL-6 in the treatment group was able to inhibit the increase in IL-6 better than the control group. Although statistically 
Table 4: The levels of IL-6 healthy groups, treatment, and control

\begin{tabular}{|c|c|c|c|c|c|}
\hline \multirow{2}{*}{ Group (n) } & \multicolumn{5}{|c|}{ Serum IL-6 Level (ng/L) } \\
\hline & Week 0 & Range & Week 4 & Range & $\mathrm{p}$ \\
\hline Healthy (14) & $26.36 \pm 21.78$ & $0-77.26$ & & & $0.83^{b}$ \\
\hline Treatment (10) & $39.6 \pm 43.54$ & $10.24-158.50$ & $45.74 \pm 44.59^{\mathrm{a}}$ & $8.1-167.41$ & \\
\hline Control (12) & $51.59 \pm 84.51$ & $0-312.17$ & $47.20 \pm 45.15^{\mathrm{a}}$ & $9.1-180.7$ & \\
\hline
\end{tabular}

significant, there was no significant difference with a t-test of significance of 0.940 ( $p>0.05)$.

Table 5: Percentage of change in serum IL-6 levels $(n=22)$

\begin{tabular}{lll}
\hline Group & Serum IL-6 Level (nmol/L) & \\
\cline { 2 - 3 } & $(\%)$ & $\mathrm{p}$ \\
\hline Treatment & $36.44 \pm 66.46$ & 0.940 \\
Control & $92.88 \pm 168.24$ & \\
\hline IL: Interleukin &
\end{tabular}

In the treatment group, liver function tests were performed at week 0 and week 4 . To determine the effect of adjuvant $N$. sativa on changes in liver function, it is shown in Table 6 . The SGOT examination at weeks 0 and 4 had the same results. A total of 9 people with normal levels (90\%) and 1 person increased (10\%). Meanwhile, the SGPT examination at week 0 and week 4 were all normal (100\%).

Table 6: Results of liver function tests for treatment subjects

\begin{tabular}{|c|c|c|c|c|c|}
\hline \multirow[t]{2}{*}{ Variable } & \multirow{2}{*}{$\begin{array}{l}\text { Referral Value } \\
(U / L)\end{array}$} & \multicolumn{2}{|c|}{ Week 0} & \multicolumn{2}{|c|}{ Week 4} \\
\hline & & $\mathrm{n}=10$ & $\%=100$ & $n=10$ & $\%=100$ \\
\hline \multirow[t]{2}{*}{ SGOT } & $<35$ & 9 & 90 & 9 & 90 \\
\hline & $>35$ & 1 & 10 & 1 & 10 \\
\hline \multirow[t]{2}{*}{ SGPT } & $<45$ & 10 & 100 & 10 & 100 \\
\hline & $>45$ & 0 & 0 & 0 & 0 \\
\hline
\end{tabular}

SGOT: Serum Glutamic Oxaloacetic Transaminase, SGPT: Serum Glutamic Pyruvic Transaminase.

\section{Discussion}

This study was conducted based on several literatures which state that the etiology of schizophrenia is caused by inflammation. That is on hypothesis vulnerabilities-stress-inflammation schizophrenic [25] and associated with abnormal cytokine levels the Schizophrenia [3]. Hence, it is hoped that the presence of anti-inflammatory agents as adjuvants can reduce the etiology of schizophrenia so that clinical symptoms of schizophrenia can be improved which are assessed using the PANSS scale and reduce the cytokine, namely, IL-6.

In this study showed a decrease in the value of PANSS at week 4 , both the control group and the treatment group. The decrease in PANSS value was significant at $p=0.05$ in the treatment group and $p=0.02$ in the control group. The decrease in PANSS values in both groups was the effect of the antipsychotic drug risperidone $4 \mathrm{mg} /$ day which was used as therapy in both study groups. Risperidone is an atypical antipsychotic that can improve positive and negative symptoms in schizophrenia [26]. There was a significant difference in the comparison of the PANSS values in the treatment and control groups at week 4 with $p<0.001$. These results indicate a significant decrease in PANSS values in the treatment group after receiving adjuvant $N$. sativa $1000 \mathrm{mg} /$ day at week 4 . This condition was associated with the anti-inflammatory and antioxidant properties of N. sativa [17].

The anti-inflammatory agent used in this study was $N$. sativa of $1000 \mathrm{mg}$. Nature pharmacy from $N$. sativa especially in quinone constituents. It was disclosed that thymol, TQ, dimmer, and thymohydroquinone are the main pharmacologically active ingredients of $N$. sativa [27]. $N$. sativa has one of the most important active components, namely, TQ. TQ exerts anti-inflammatory properties by inhibiting its production [6]. One study showed that administration of TQ significantly decreased the expression of inflammatory cytokines, IL-2 = 38\%, IL-4 = 19\%, $\mathrm{IL}-6=83 \%$, IL-10 = 23\%, and IL-17 a = 29\%, in activated microglia compared with untreated. TQ increased neuronal protein expression while decreasing cytokine expression and expression of the pro-inflammatory gene NFKB signaling pathway target in BV-2-activated LPS/IFN $\gamma$ microglia cells [9].

$N$. sativa which has anti-inflammatory properties [19] and antioxidants [28] through its active substance, TQ is estimated to improve clinical symptoms of schizophrenia as seen in the significant improvement in the PANSS value in the treatment group compared to the control group. The results of a meta-analysis of sixty double-blind randomized clinical trials (RCTs) studying 2914 patients with schizophrenia showed that anti-inflammatory agents significantly reduced the total score with positive and negative symptoms in PANSS scores [29]. Significantly on anti-inflammatory agents reduced the total score, positive and negative symptoms in PANSS scores [29]. In 22 RCTs of varying quality and sample size studying Ginkgo biloba, $\mathrm{N}$-acetyl cysteine, allopurinol, dehydroepiandrosterone, Vitamin C, Vitamin E, or selegiline. There were three studies with short-term data for this outcome (there was a $20 \%$ improvement in PANSS scores) and in 7 RCTs lower psychotic symptoms based on PANSS scores in subjects taking antioxidants [30]. The results also showed that positive symptoms showed the fastest decrease in week 4 based on the rate of symptom reduction in the treatment group compared to negative and general symptoms with a significance of $<0.001$.

In healthy controls taken in this study as many as 14 people had an average serum IL-6 level $26.36 \pm 21.78 \mathrm{ng} / \mathrm{L}$ with a range of serum IL-6 levels of $0-77.26 \mathrm{ng} / \mathrm{L}$ lower than the mean of the schizophrenia group. In some literature, it is said IL-6 in healthy condition, the level is $<4 \mathrm{pg} / \mathrm{ml}$, but when there is stress such as infection or injury. Serum IL-6 levels increase to several tens to hundreds of $\mathrm{pg} / \mathrm{ml}$, depending on infection or injury [31], [32]. Many factors can increase IL-6 levels, including BMI, depression [33], [34], after stress [34], immune reaction [35], and smoking. One 
study showed differences in the range of IL-6 levels, healthy controls who smoked at $1.51-27.6 \mathrm{pg} / \mathrm{ml}$ and did not smoke $0.09-19.1 \mathrm{pg} / \mathrm{ml}$ [36]. Where the healthy controls were not screened for the presence of stress and depression disorders, when IL-6 blood samples were taken. In a study of depressed $(n=12)$ and schizophrenic $(n=32)$ patients during the acute state of illness and after remission approximately 8 weeks after admission and compared with healthy controls $(n=12)$, concentrations of cytokines such as IL-6plasma have been reported to be elevated in depressed and schizophrenic patients and in healthy individuals, after stress [34].

The mean serum IL-6 levels of schizophrenic patients in this study tended to be higher than healthy controls. These results are in accordance with several studies that discussed the relationship of elevated serum IL-6 levels with clinical symptoms of schizophrenia patients. Schizophrenia and people who experience brief or mild symptoms (classically described as the prodromal stage) are considered to be at clinical high risk for the disease. For FEP, significant increases in serum IL $1 \beta$, sIL $2 r$, IL-6, IL-12, TNF-, TGF, and IFN- $\gamma$, together with decreased IL-10 in acute relapse. In a meta-analysis, IL-1 $\beta$, IL-6, and TGF- $\beta$ could be markers, given their elevated levels in acute episodes followed by normalization under antipsychotic treatment [37]. In this study, serum IL-6 levels were examined. The significance of the difference in serum IL- 6 levels in the treatment and control groups was $p=0.83$, the results were not significant. This may be due to the small size of the sample included in this study and the relatively short study period of 4 weeks.

Observation week 4 on the mean serum IL-6 levels in the control group tended to decrease from 51.59 $\pm 84.51 \mathrm{ng} / \mathrm{L}$ to $47.20 \pm 45.15 \mathrm{ng} / \mathrm{L}$. This decrease in serum IL-6 levels is in accordance with previous studies that in patients treated with risperidone, serum levels of IL-6 and IL-2 decreased after 4 weeks compared to levels before antipsychotic therapy [38]. In another study after 2 months of treatment with a typical or atypical antipsychotic (such as risperidone), IL-6 levels appeared to decrease. [3] One study showed that risperidone normalized the increase in inflammatory mediators (cytokines and prostaglandin) [39]. The presence of antipsychotic anti-inflammatory effects suggests a major role for inflammation in schizophrenia [4]. A meta-analysis showed a significant reduction in serum IL-6 after risperidone treatment. In some cases, changes in IL-6 levels can be affected by region or duration of treatment. Treatment with risperidone on FEDN significantly suppressed the immune response system in particular, the inflammatory marker IL-6 was significantly reduced. In that study, risperidone affected astrocytes and C6 astroglia, by reducing the release of IL-6. In addition, risperidone inhibits IL-6-induced S100B secretion, reducing the level of secretion below the basal level. Risperidone can attenuate microglia activation in the brain, which may decrease IL-6 levels [26]. Serum IL-6 levels may also increase after 3 months of taking risperidone and clozapine in patients with the metabolic syndrome [40].

In the treatment group, the mean serum IL-6 level was seen to increase by $39.6 \pm 43.54 \mathrm{ng} / \mathrm{L}$ becomes $45.74 \pm 44.59 \mathrm{ng} / \mathrm{L}$. However, serum IL-6 levels treatment group at week 4 almost the same compared to the control group at $47.20 \pm 45.15 \mathrm{ng} / \mathrm{L}$. The percentage rate of change in serum IL-6 levels indicates a biologic effect of $N$. sativa as adjuvant therapy. The results showed that the percentage increase in serum IL-6 levels in the treatment group was $36.44 \pm 66.46$ and the control group was $92.88 \pm$ 168.24. These results indicate that the treatment group in the presence of $N$. sativa adjuvants was able to inhibit the increase in serum IL-6 levels were better than the control group. In line with studies in septic mice show that TQ suppresses the acute inflammatory response by significantly inhibiting levels of cytokines, including TNF-, IL-1 $\alpha$, IL-2, IL-6, and IL-10 [18].

Changes in IL-6 levels may be well visible after 3 months of treatment. According to one study, changes in cytokines differed in various clinical conditions that increased in first-episode psychosis and acute relapse, and were normalized by antipsychotic treatment and decreased markedly after 3 months of treatment antipsychotic and minocycline adjuvants [41]. In other studies, there has been no study on the dose of $N$. sativa as an adjuvant therapy that will decrease IL-6 levels in schizophrenic patients, so there is no precise reference to the dose of $N$. sativa. In another study with human research subjects using $N$. sativa on 94 patients with type 2 diabetes mellitus took $N$. sativa 1000,2000 , and $3000 \mathrm{mg} /$ day for 3 months. Result a dose of $2000 \mathrm{mg} /$ day significantly reduced fasting blood sugar, $2 \mathrm{~h}$ postprandial and $\mathrm{HbA} 1 \mathrm{c}$. Doses of $1000 \mathrm{mg} /$ day showed an improvement trend but not significant. Lack of response at a dose of $3000 \mathrm{mg} /$ day [42] so that in future studies can observe the use of larger doses.

Risperidone $4 \mathrm{mg}$ was used as antipsychotic therapy in schizophrenic patients in this study, in which an adjuvant $N$. sativa was added to the treatment group. Risperidone is metabolized by cytochrome P450 (CYP) 2D6. In addition, the literature highlights the inhibitory effect of CYP2D6 drugs that interact with risperidone [43]. One of the studies show that there is a high probability of drug interactions and co-administration of TQ or TQ-containing substances with drugs metabolized by CYP enzymes. Inhibition of CYP enzyme activity by $\mathrm{TQ}$ was evaluated by incubating typical substrates (phenacetin for CYP1A2, tolbutamide for CYP2C9, dextromethorphan for CYP2D6, and testosterone for CYP3A4) [22]. Hence, it is necessary to pay attention to its long-term effect on the metabolism of risperidone in the liver which is inhibited by TQ. 
To observe the side effects of adjuvant $N$. sativa in the treatment group $(n=10)$ receiving risperidone antipsychotic therapy, liver function tests were performed, namely, Serum Glutamic Oxaloacetic Transaminase (SGOT) and Serum Glutamic Pyruvic Transaminase (SGPT). At week 0 of the SGOT examination, nine people had normal levels (90\%) and one person increased $(10 \%)$. At week 4 , the results of the liver function test category did not change the category of liver function test results. Similarly, in the SGPT examination of 10 (100\%) research subjects in the treatment group, the category of the results of the SGPT examination did not change at week 4 , it was still within the normal reference value.

The results of liver function tests are in accordance with one of the studies conducted on twentyfour male Sprague Dawley rats. The results showed that $N$. sativa supplementation up to a dose of $1 \mathrm{~g} / \mathrm{kg}$ for 28 days did not cause changes in liver enzyme levels and did not cause a toxic effect on liver function as indicated by the absence of significant changes in serum ALT and AST between the treatment groups [44]. In another study assessed the protective effect of $\mathrm{TQ}$ against Acrylamide (AA)-induced toxicity in forty-eight male Wistar. Administration of TQ normalized AA-induced changes in most serum parameters and increased antioxidant capacity in liver, kidney, and brain tissues [45]. Administration of $N$. sativa $1000 \mathrm{mg} /$ day for 9 weeks in 40 male subjects aged around 55 years showed that biochemical markers of heart, liver, and kidney function were significantly unchanged [14]. However, in the period of more than 4 weeks, it is necessary to re-examine liver function to determine the side effects of adjuvant $N$. sativa in patients receiving risperidone therapy.

\section{Conclusion}

The value of PANSS in both the treatment and control groups decreased by week 4 . Both trial groups showed an improvement in clinical symptoms. When schizophrenic patients on $4 \mathrm{mg}$ risperidone were given adjuvant $N$. sativa $1000 \mathrm{mg}$, the PANSS score in the treatment group was considerably higher improvement than in the control group. Healthy controls had lower baseline serum IL-6 levels than schizophrenia subject. The treatment and control group's serum IL-6 levels were not substantially different at week 4 . The treatment group had a faster percentage response to the drop in serum IL-6 levels, indicating that $N$. sativa had a biological effect on IL-6 levels. The decrease in PANSS values was negatively linked with serum IL-6 levels, and the mechanism that assisted in the reduction of PANSS values was faster in the group. At week 4, the treatment was compared to the control group. Giving adjuvant $N$. sativa $1000 \mathrm{mg}$ to the treatment group for 4 weeks had no effect on the liver function tests,
SGOT and SGPT, indicating that it was safe to use as adjuvant therapy.

\section{References}

1. Upthegrove R, Khandaker GM. Cytokines, oxidative stress and cellular markers of inflammation in schizophrenia. Curr Top Behav Neurosci. 2020;44:49-66. https://doi. org/10.1007/7854_2018_88

PMid:31115797

2. Stojanovic A, Martorell L, Montalvo I, Ortega L, Monseny R, Vilella $\mathrm{E}$, et al. Increased serum interleukin-6 levels in early stages of psychosis: Associations with at-risk mental states and the severity of psychotic symptoms. Psychoneuroendocrinology. 2014;41:23-32. https://doi.org/10.1016/j.psyneuen.2013.12.005 PMid:24495605

3. Momtazmanesh S, Zare-Shahabadi A, Rezaei N, GarciaGutierrez MS, Schiavone S, Arsenijevic NN. Cytokine alterations in schizophrenia: An updated review. Front Psychiatry. 2019;10:892. https://doi.org/10.3389/fpsyt.2019.00892

\section{PMid:31908647}

4. Müller N, Weidinger E, Leitner B, Schwarz MJ, Powell S. The role of inflammation in schizophrenia. Front Neurosci. 2015;9:372 https://doi.org/10.3389/fnins.2015.00372

PMid:26539073

5. Tavakkoli A, Mahdian V, Razavi BM, Hosseinzadeh $\mathrm{H}$ Review on clinical trials of black seed (Nigella sativa) and its active constituent, thymoquinone. J Pharmacopuncture. 2017;20(3):179-93. https://doi.org/10.3831/KPI.2017.20.021 PMid:30087794

6. Ahmad A, Husain A, Mujeeb M, Khan SA, Najmi AK, Siddique NA et al. Review on therapeutic potential of Nigella sativa: A miracle herb. Asian Pac J Trop Biomed. 2013;3(5):337-52. https://doi. org/10.1016/S2221-1691(13)60075-1

PMid:23646296

7. Shahdaat M, Sayeed B, Shams T, Hossain SF, Rahman R, MostofaAG, et al. Nigella sativa L. seeds modulate mood, anxiety and cognition in healthy adolescent males. J Ethnopharmacol. 2014;152(1):156-62. https://doi.org/10.1016/j.jep.2013.12.050 PMid:24412554

8. Hosseini M, Zakeri S, Khoshdast S. The effects of Nigella sativa hydro-alcoholic extract and thymoquinone on lipopolysaccharide induced depression like behavior in rats. J Pharm Bioallied Sci. 2012;4(3):219-25. https://doi.org/10.4103/0975-7406.99052 PMid:22923964

9. Cobourne-Duval MK, Taka E, Mendonca P, Soliman KF. Thymoquinone increases the expression of neuroprotective proteins while decreasing the expression of pro-inflammatory cytokines and the gene expression NF $\kappa B$ pathway signaling targets in LPS/IFN $\gamma$-activated BV-2 microglia cells. J Neuroimmunol. 2018;320:87-97. https://doi.org/10.1016/j. jneuroim.2018.04.018 PMid:29759145

10. Hobbenaghi R, Javanbakht J, Sadeghzadeh S, Kheradmand D, Abdi FS, Jaberi MH. Neuroprotective effects of Nigella sativa extract on cell death in hippocampal neurons following experimental global cerebral ischemia-reperfusion injury in rats. J Neurol Sci. 2014;337(1-2):74-9. https://doi.org/10.1016/j. jns.2013.11.019

PMid:24314720

11. Kanter ML, Kalayci M, Buyukbas S, Cagavi F. Neuroprotective 
effiects of Nigellca sativa on experimental spinat cord injury in rats. Hum Exp Toxicol. 2006;25(3):127-33. https://doi. org/10.1191/0960327106ht608oa

PMid:16634331

12. Yazdi S, Noorbakhsh H, Foad M, Farkhondeh T. An overview on renoprotective effects of thymoquinone. Kidney Dis. 2018;2018:9318614139.

13. Adam GO, Rahman M, Lee SJ, Kim GB, Kang HS, Kim JS, et al. Hepatoprotective effects of Nigella sativa seed extract against acetaminophen-induced oxidative stress. Asian Pac J Trop Med. 2016;9(3):221-7. https://doi.org/10.1016/j.apjtm.2016.01.039 PMid:26972391

14. Sayeed MS, Asaduzzaman M, Morshed H, Hossain MM, Kadir MF, Rahman MR. The effect of Nigella sativa Linn. seed on memory, attention and cognition in healthy human volunteers. J Ethnopharmacol. 2013;148(3):780-6. https://doi.org/10.1016/j. jep.2013.05.004

PMid:23707331

15. Bargi R, Asgharzadeh F, Beheshti F, Hosseini M, Sadeghnia HR, Khazaei M. The effects of thymoquinone on hippocampal cytokine level, brain oxidative stress status and memory deficits induced by lipopolysaccharide in rats. Cytokine. 2017;96:173-84. https://doi.org/10.1016/j.cyto.2017.04.015 PMid:28432986

16. Velagapudi R, Kumar A, Bhatia HS, El-Bakoush A, Lepiarz I, Fiebich $\mathrm{BL}$, et al. Inhibition of neuroinflammation by thymoquinone requires activation of Nrf2/ARE signalling. Int Immunopharmacol. 2017;48:17-29. https://doi.org/10.1016/j. intimp.2017.04.018

PMid:28458100

17. Mohit M, Farrokhzad A, Nooreddin S, Heidarzadeh-esfahani $\mathrm{N}$ Kafeshani M. Complementary therapies in medicine effect of Nigella sativa L. supplementation on inflammatory and oxidative stress indicators: A systematic review and meta-analysis of controlled clinical trials. Complement Ther Med. 2020;54:102535. https://doi.org/10.1016/j.ctim.2020.102535 PMid:33183658

18. Alkharfy KM, Ahmad A, Jan BL, Raish M. Thymoquinone reduces mortality and suppresses early acute inflammatory markers of sepsis in a mouse model. Biomed Pharmacother. 2018;98:801-5. https://doi.org/10.1016/j.biopha.2018.01.028 PMid:29571249

19. Ali BH, Blunden $\mathrm{G}$. Pharmacological and toxicological properties of Nigella sativa. Phytother Res. 2003;17(4):299-305. https:// doi.org/10.1002/ptr.1309 PMid:12722128

20. Hamed MA, El-Rigal NS, Ali SA. Effects of black seed oil on resolution of hepato-renal toxicity induced bybromobenzene in rats. Eur Rev Med Pharmacol Sci. 2013;17(5):569-81. PMid:23543440

21. Zaghlol DA, Kamel ES, Mohammed DS, Abbas NH. The possible toxic effect of different doses of Nigella sativa oil on the histological structure of the liver and renal cortex of adult male albino rats. Egypt J Histol. 2012;35(1):127-36. https://doi. org/10.1097/01.EHX.0000411396.11951.02

22. Albassam AA, Ahad A, Alsultan A, Al-Jenoobi FI. Inhibition of cytochrome P450 enzymes by thymoquinone in human liver microsomes. Saudi Pharm J. 2018;26(5):673-7. https://doi. org/10.1016/j.jsps.2018.02.024

PMid:29989011

23. Ali B, Amin S, Ahmad J, Ali A, Ali M, Mir SR. Bioavailability enhancement studies of amoxicillin with Nigella. Indian $\mathrm{J}$ Med Res. 2012;135(4):555-9.

PMid:22664507
24. Rashid AK, Abul KN, Arshad HK, Darpan G, Mohd A. Ameliorating effects of thymoquinone in rodent models of schizophrenia. Afr J Pharm Pharmacol. 2014;8(15):413-21.

25. Müller N. COX- inhibitors, aspirin, and other potentia anti-inflammatory treatments for psychiatric disorders inflammation and depression risk. Front Psychiatry. 2019;10:375. https://doi.org/10.3389/fpsyt.2019.00375 PMid:31214060

26. Feng Z, Zhang Y, You X, Zhang W, Ma Y, Long Q, et al. Effects of risperidone on blood levels of interleukin-6 in schizophrenia: A meta-analysis. Medicine. 2020;99(15):e19694. https://doi. org/10.1097/MD.0000000000019694

PMid:32282724

27. Mazaheri $\mathrm{Y}$, Torbati M, Azadmard-Damirchi S, Savage GP A comprehensive review of the physicochemical, quality and nutritional properties of Nigella sativa oil a comprehensive review of the physicochemical, quality and nutritional properties of Nigella sativa oil. Food Rev Int. 2019;35(4):342-62.

28. Nagi MN, Mansour MA. Protective effect of thymoquinone against doxorubicin induced cardiotoxicity in rats: A possible mechanism of protection. Pharmacol Res. 2000;41(3):283-9. https://doi.org/10.1006/phrs.1999.0585 PMid:10675279

29. Cho M, Lee TY, Kwak YB, Yoon YB, Kim M, Kwon JS. Adjunctive use of anti-inflammatory drugs for schizophrenia: A meta analytic investigation of randomized controlled trials. Aust N Z J Psychiatry. 2019;53(8):742-59. https://doi. org/10.1177/0004867419835028 PMid:30864461

30. Magalhães PV, Dean O, Andreazza AC, Berk M, Kapczinski F. Antioxidant treatments for schizophrenia. Cochrane Database Syst Rev. 2016;2:CD008919. https://doi.org/10.1002/14651858. CD008919.pub2 PMid:26848926

31. Tanaka T, Narazaki M, Masuda K, Kishimoto T. Regulation of IL-6 in immunity and diseases. In: Ma X, editor. Regulation of Cytokine Gene Expression in Immunity and Diseases. Berlin: Springer Science; 2016. p. 79-88.

32. Khandaker GM, Cousins L, Deakin J, Lennox BR, Yolken R, Jones PB. Infl ammation and immunity in schizophrenia: Implications for pathophysiology and treatment. Lancet Psychiatry. 2015;2(3):258-70. https://doi.org/10.1016/ S2215-0366(14)00122-9 PMid:26359903

33. Lee ST. Inflammation, depression, and anxiety disorder: A population-based study examining the association between Interleukin- 6 and the experiencing of depressive and anxiety symptoms. Psychiatry Res. 2020;285:112809.

34. Frommberger $U H$, Bauer $J$, Haselbauer $P$, Fräulin $A$, Riemann D, Berger M. Interleukin-6-(IL-6) plasma levels in depression and schizophrenia: Comparison between the acute state and after remission. Eur Arch Psychiatry Clin Neurosci. 1997;247(4):228-33. https://doi.org/10.1007/BF02900219 PMid:9332905

35. Tanaka T, Narazaki M, Kishimoto T. IL-6 in inflammation, immunity, and disease. Cold Spring Harb Perspect Biol. 2014;6(10):a016295. https://doi.org/10.1101/cshperspect.a016295 PMid:25190079

36. Siagian D. Perbedaan Kadar Serum Interleukin-6 pada Kanker Paru Perokok dan Tidak Perokok. Sumatera Utara; 2018.

37. Trovão N, Prata J, Vondoellinger O, Santos S, Barbosa M, Coelho R. Peripheral biomarkers for first-episode psychosisopportunities from the neuroinflammatory hypothesis of schizophrenia. Psychiatry Investig. 2019;16(3):177-84 
https://doi.org/10.30773/pi.2018.12.19.1

PMid:30836740

38. Lü LX, Guo SQ, Chen W, Li Q, Cheng J, Guo JH. Effect of clozapine and risperidone on serum cytokine levels in patients with first-episode paranoid schizophrenia. Di Yi Jun Yi Da Xue Xue Bao. 2004;24(11):1251-4.

PMid:15567770

39. Leza JC, García-bueno B, Bioque M, Arango C, Parellada M, Do $\mathrm{K}$, et al. Neuroscience and biobehavioral reviews inflammation in schizophrenia: A question of balance. Neurosci Biobehav Rev. 2015;55:612-26. https://doi.org/10.1016/j. neubiorev.2015.05.014 PMid:26092265

40. Saidah S, Sonny LT, Lilik H, Burhanuddin B, Haerani R, Wempy T. Levels of interleukin 6 as a predictor of metabolic syndrome in schizophrenic patients receiving combination therapy of typical and atypical antipsychotics. Open Access Maced J Med Sci. 2021;9:600-7. https://doi.org/10.3889/oamjms.2021.6378

41. Kosten TR, Zhang $\mathrm{L}$, Zheng $\mathrm{H}$, Wu R, Zhu F, Zhang $\mathrm{X}$, et al. Minocycline adjunctive treatment to risperidone for negative symptoms in schizophrenia Association with pro-inflammatory cytokine levels. Prog Neuropsychopharmacol Biol Psychiatry.
2018;85:69-76. https://doi.org/10.1016/j.pnpbp.2018.04.004

PMid:29678772

42. Bamosa AO, Kaatabi H, Lebda FM, Al Elq AM, Al-Sultan A. Effect of Nigella sativa seeds on the glycemic control of patients with Type 2 diabetes mellitus. Indian J Physiol Pharmacol. 2010;54(4):344-54.

PMid:21675032

43. De Leon J. CYP2D6 genetic polymorphisms and risperidone pharmacokinetics: A systematic review and meta-analysis. 2020;40(7):632-47. https://doi.org/10.1002/phar.2434

PMid:32519344

44. Dollah MA, Parhizkar S, Latiff LA, Hassan MH. Toxicity effect of Nigella sativa on the liver function of rats. Adv Pharm Bull. 2013;3(1):97-102. https://doi.org/10.5681/apb.2013.016 PMid:24312819

45. Abdel-Daim MM, Abo El-Ela FI, Alshahrani FK, Bin-Jumah M, $\mathrm{Al}$-Zharani M, Almutairi $\mathrm{B}$, et al. Protective effects of thymoquinone against acrylamide-induced liver, kidney and brain oxidative damage in rats. Environ Sci Pollut Res. 2020;27(30):37709-17. https://doi.org/10.1007/s11356-020-09516-3

PMid:32608003 